\title{
Intumescent coatings with improved properties for high-rise construction
}

\author{
Andrey Ustinov ${ }^{1,2 *}$, Olga Zybina ${ }^{1}$, Leonid Tanklevsky ${ }^{1}$, Vasily Lebedev ${ }^{2}$, and Andrey \\ Andreev $^{3}$ \\ ${ }^{1}$ Peter the Great St. Petersburg Polytechnic University, Higher School of Technospheric Safety, Fire \\ Safety Department, 29 Polytechnicheskaya st., St.Petersburg, 195251, Russia \\ ${ }^{2}$ Petersburg Nuclear Physics Institute, Neutron Research Department, Condensed state research \\ division, Laboratory of neutron physico-chemical researches, PNPI, 1, Orlova roscha mcr., Gatchina, \\ Leningrad region, 188300, Russia \\ ${ }^{3}$ Peter the Great St. Petersburg Polytechnic University, Higher School of Technospheric Safety, 29 \\ Polytechnicheskaya st., St.Petersburg, 195251, Russia
}

\begin{abstract}
The paper overviews the way of creating intumescent fireprotective compositions with improved properties by adding nano- and micro-sized supplements into them. Intumescent paints are inert at low temperatures, and at higher temperatures they expand and degrade to provide a charred layer of low conductivity materials. The modified intumescent paints are able to form a more stable charred layer than the classical paints. The stability of a charred layer is crucial if the fire safety in high-rise construction must be secured, because a weak charred layer will not provide a required fire endurance for steel bearing structures and they will break down in case of fire. The fire-protective properties of modified intumescent paints were estimated using an electrical furnace. Also the way of thermal decomposition of the paints was studied with thermogravimetric analysis. Results show that modified intumescent paints form a charred layer with improved fire-protective properties; it can serve as a thermal barrier for a longer period of time. Thermogravimetric analysis confirms this fact showing that the temperatures of full thermal decay in case of modified paints are higher than those of non-modified paints.
\end{abstract}

\section{Introduction}

Intumescent fire-protective paints are now one of the most common instruments for ensuring the fire protection of modern buildings. As was mentioned in the abstract, an intumescent coating swells as a result of heat exposure forming a charred layer which serves as a thermal barrier and does not let fire and heat to the protected surface [1]. This means that the protected construction will be able to keep fire-resistant and load-carrying properties for a longer period of time. This fact is important for high-rise buildings, large public places, airports and etc.

One of the main problems of using intumescent paints is a fire protection of steel constructions, which are commonly used in buildings mentioned in a previous paragraph. As a research [2] showed, a steel construction loses a significant part of its load carrying ability

\footnotetext{
* Corresponding author: ustinov.andrey1994@gmail.com
} 
when the temperature in case of fire exceeds $500{ }^{\circ} \mathrm{C}$. The temperature of real fire is about $800-1000^{\circ} \mathrm{C}$ and it means that the steel constructions are extremely heated and may lose their required properties in a short period of time. If a steel construction is protected by an intumescent coating, we face another circumstance: an adhesion of a charred intumescent layer to a heated steel is very low [3], and a charred layer will simply fall off from a surface. Also an intumescent layer which, in general, is a carbon-polymer matrix may burn out when the temperature of fire exceeds $1000{ }^{\circ} \mathrm{C}$ [4]. All these problems show the necessity of some changes in classical intumescent compositions to make them more reliable when we speak about the fire protection on high-rise and large buildings.

As the effective compositions of ingredients in intumescent paints have already been discovered [5], there is no purpose in changing these compositions. One of the ways of improving the properties of intumescent paints and the charred layers formed by them is adding different supplements into a composition. These supplements do not change the structure of the paint, but they can have a significant impact on the fire-protective properties of a forming charred layer.

The subject of a research is an intumescent paint for steel constructions produced by «Gefest» Enterprise group and based on ammonium polyphosphate, pentaerythritol and melamine. The additives used to improve the properties of this paint were fullerenecontaining soot, glass microspheres and aluminosilicate microspheres.

Fullerene-containing soot is a product of the first subprocess of fullerene production; it contains of graphite's microparticles and non-purified fullerenes with different structure $\left(\mathrm{C}_{60}\right.$, $\mathrm{C}_{70}$ etc.). Such material may have a great impact on the properties of intumescent coatings [6], because a charred layer is basically a carbon matrix which can easily accept another carbon materials, such as graphite and fullerenes; the last ones have proven themselves as strengthening additives [3] which can protect a charred layer from destruction and parching [7]. Microspheres are microscopic spheres of glass, aluminosilicate and etc. which are usually between 1 and 1000 micrometers in diameter, although the sizes can range from 100 nanometers to 5 millimeters in diameter. As the microspheres are hollow their heat conductivity is low, and due to this fact they can lower the conductivity of a charred intumescent layer making it more effective and stable.

The purpose of the paper was to estimate the properties of an improved intumescent paints; the way of heat decomposition of those paints was also needed to be investigated.

\section{Materials and Methods}

As was mentioned in a previous section, the paper overviews the properties of an intumescent paint for steel constructions modified by fullerene-containing soot and microspheres. The paint itself is presented on the Russian market of fireproof materials. Microspheres are also a well-known product.

Fullerene-containing soot was produced in PNPI as a result of burning the graphite electrode (filled with ferrum phthalocyanine) in a voltaic arc by the method [8]. The soot is quite a cheap product and it can be used in an industrial production of modified intumescent paints. The soot used in this research contained of graphite, fullerenes $\mathrm{C}_{60}, \mathrm{C}_{70}$, and ferrum endohedral fullerenes Fe@ $\mathrm{C}_{\mathrm{n}}$.

Additives were mixed with the paint; samples of modified paint were applied on steel plates $(30 \times 91 \mathrm{~mm}$ and $1 \mathrm{~mm}$ thick). Painted plates were placed in an electrical furnace and were heated with $600{ }^{\circ} \mathrm{C}$ by $5 \mathrm{~min}$. The purpose of this procedure was to estimate the swelling coefficient of the paints as a quotient between the initial thickness of the coating and the thickness of a charred layer. This coefficient shows the efficiency of an intumescent paint in case of a fire. 
Also the thermal conductivity of modified intumescent coatings was studied. Samples of paints were applied on steel tubes $(15 \mathrm{~mm}$ in diameter). Painted tubes were also placed in an electrical furnace $\left(600^{\circ} \mathrm{C}\right)$. As the tubes were hollow, the chromel-alumel thermocouples were placed in them to watch the temperature inside the tubes. The purpose of an experiment was to find the paint which forms a charred layer with the lowest thermal conductivity; it was estimated by the period of time which a painted steel tube needs to reach the critical temperature of $500{ }^{\circ} \mathrm{C}$; the more time it takes, the lower thermal conductivity a charred layer has, and due to this the construction's surface will start heating later.

Modified paints were also studied with thermogravimetric analysis (TGA) using a Derivatograph Q-1500D, J. Paulik, P. Paulik, and I. Erdey system, by «MOM» Hungary. The principles of this technique are described in [9]. In brief, a derivatograph simultaneously measures the parameters of a sample brought about by heating it: change in weight (thermogravimetry, TG curve), rate of the change in weight (derivative thermogravimetry, DTG curve), change in enthalpy (differential thermal analysis, DTA curve). These curves are automatically registered as a function of temperature or time. Results of thermogravimetric analysis provide qualitative and quantitative information about the processes which take place in a material while heating it.

\section{Results}

Table 1 represents the samples of modified intumescent paints, the type of additives and their quantity in each sample.

Table 1. Samples of modified intumescent paint

\begin{tabular}{|c|c|c|}
\hline N of the sample & Additive & Additives quantity, mass. $\%$ \\
\hline 1 & - & - \\
\hline 2 & Fullerene-containing soot & 1 \\
\hline 3 & Fullerene-containing soot & 3 \\
\hline 4 & Microspheres Al-Si & 10 \\
\hline 5 & Microspheres glass & 10 \\
\hline
\end{tabular}

Figures 1, 2 show the painted steel plate and tube before and after firetests. Table 2 represents the results of these tests - initial thickness of a paint layer on a steel plate, thickness of a formed charred layer, swelling coefficient, and the time of thermal barrier's existence (for tubes).

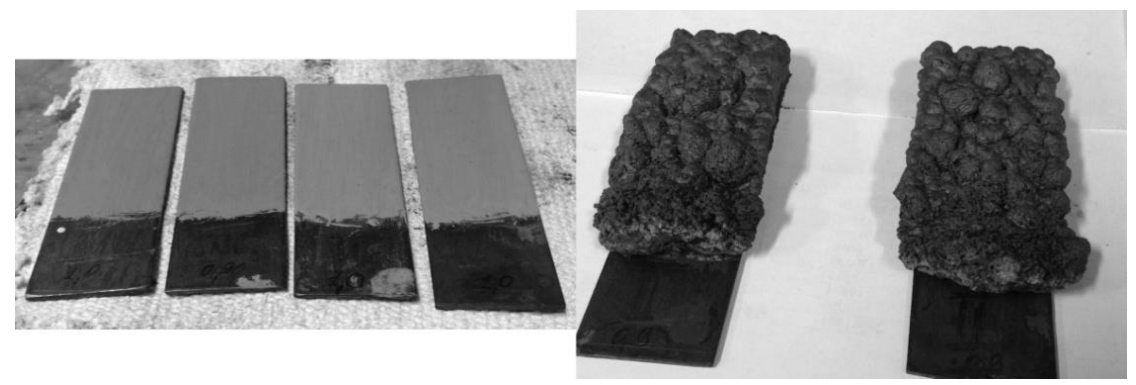

Fig. 1. Intumescent paint on steel plates before the test (left) and a charred layer formed as a result of test (right) 


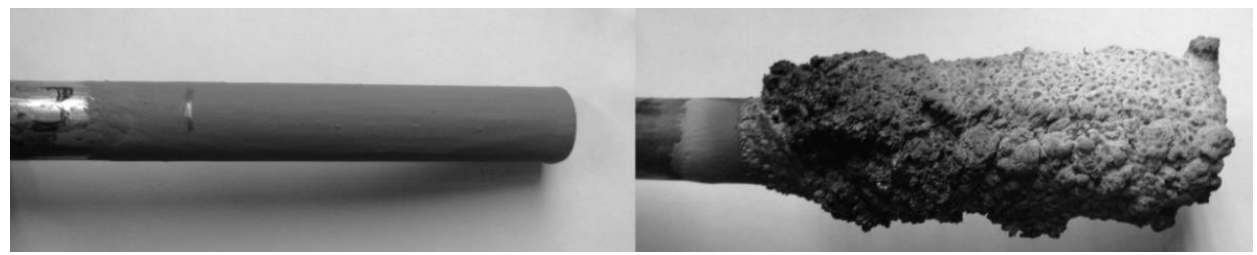

Fig. 2. Intumescent paint on steel tube before the test (left) and a charred layer formed as a result of the test (right)

Table 2. Results of firetest on steel plates and of thermal conductivity test

\begin{tabular}{|c|c|c|c|c|}
\hline $\begin{array}{c}\text { № of the } \\
\text { sample }\end{array}$ & $\begin{array}{c}\text { Initial } \\
\text { thickness, mm }\end{array}$ & $\begin{array}{c}\text { Charred layer } \\
\text { thickness, mm }\end{array}$ & $\begin{array}{c}\text { Swelling } \\
\text { coefficient }\end{array}$ & $\begin{array}{c}\text { Time of thermal } \\
\text { barrier existence, } \\
\text { min }\end{array}$ \\
\hline 1 & 0,3 & 10,1 & 33,7 & 15 \\
\hline 2 & 0,3 & 12,9 & 43 & 42 \\
\hline 3 & 0,3 & 12,2 & 40,6 & 33 \\
\hline 4 & 0,3 & 13,4 & 44,7 & 26 \\
\hline 5 & 0,3 & 13,7 & 45,7 & 23 \\
\hline
\end{tabular}

Figures 3-7 and tables 3, 4 represent the results of thermogravimetric analysis of modified paints.

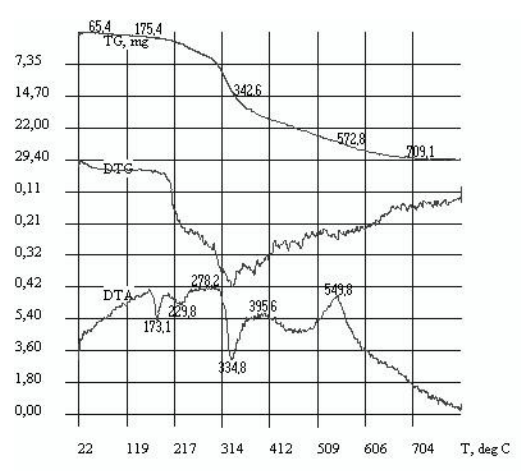

Fig. 3. Results of TGA for sample №1

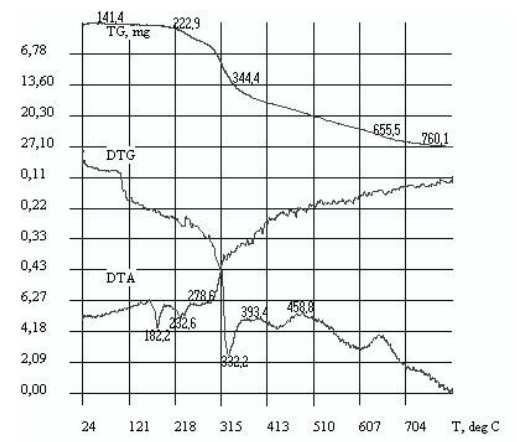

Fig. 5. Results of TGA for sample №3

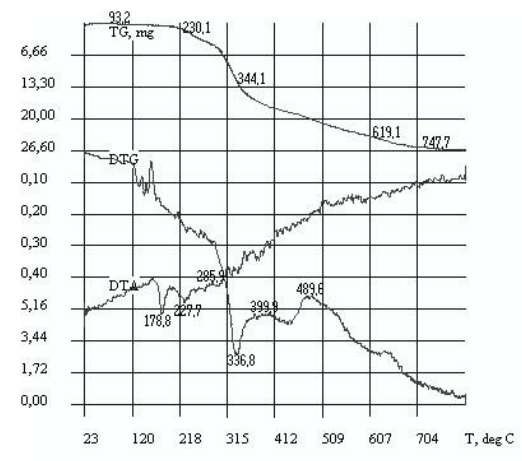

Fig. 4. Results of TGA for sample №2

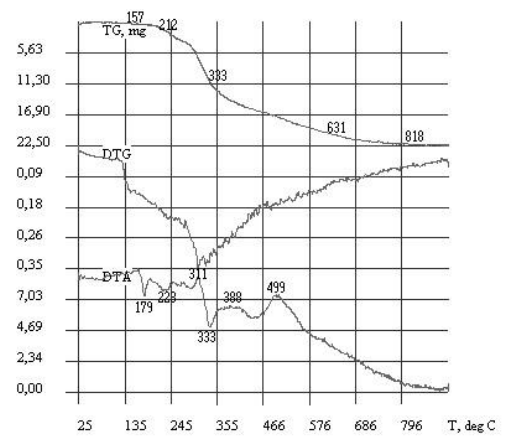

Fig. 6. Results of TGA for sample №4 


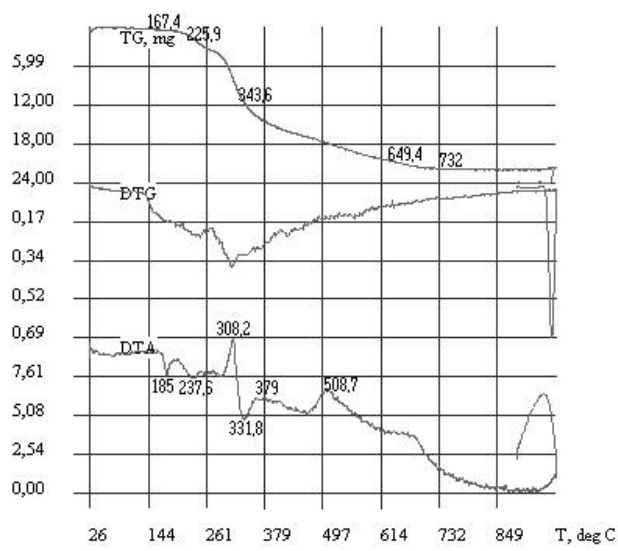

Fig. 7. Results of TGA for sample №5

Table 3. Temperatures of thermolysis stages of intumescent paints

\begin{tabular}{|c|c|c|c|c|c|}
\hline & \multicolumn{5}{|c|}{ Temperatures, ${ }^{\circ} \mathrm{C}$} \\
\hline Parameter / № of the sample & 1 & 2 & 3 & 4 & 5 \\
\hline Start of pentaerythritol decay & 173 & 179 & 182 & 179 & 185 \\
\hline Full pentaerythritol decay & 230 & 228 & 233 & 223 & 238 \\
\hline Synthesis of resins & 278 & 286 & 279 & 311 & 308 \\
\hline Ammonium polyphosphate decay & 335 & 337 & 332 & 333 & 332 \\
\hline Hardening & 396 & 400 & 393 & 388 & 379 \\
\hline Condensation & 550 & 490 & 459 & 499 & 509 \\
\hline
\end{tabular}

Table 4. Parameters describing the heat endurance of the paints

\begin{tabular}{|c|c|c|c|c|c|}
\hline Parameter $/$ № of the sample & 1 & 2 & 3 & 4 & 5 \\
\hline T of start of sample's weight decrease, ${ }^{\circ} \mathrm{C}$ & 65 & 93 & 141 & 157 & 167 \\
\hline T of $5 \%$ of sample's weight decrease, ${ }^{\circ} \mathrm{C}$ & 175 & 230 & 223 & 212 & 226 \\
\hline T of $50 \%$ of sample's weight decrease, ${ }^{\circ} \mathrm{C}$ & 343 & 344 & 344 & 333 & 344 \\
\hline T of $90 \%$ of sample's weight decrease, ${ }^{\circ} \mathrm{C}$ & 573 & 619 & 656 & 631 & 649 \\
\hline T of full decay, ${ }^{\circ} \mathrm{C}$ & 709 & 748 & 760 & 818 & 732 \\
\hline
\end{tabular}

\section{Discussion}

According to the results of firetests represented in table 2, all additives used for modification of an intumescent paint significantly increase its fire-protective properties. Swelling coefficient increased by $32-49 \%$, the best results are shown by samples 4 and 5 which comprise glass and aluminosilicate microspheres. This can be explained by the fact that microspheres are hollow, and when a charred layer is forming they release an additional 
amount of air which increases volume of a charred layer. Fullerene-containing soot acts another way: the carbon particles help in building up the polymer matrix of a charred layer making it more solid and anisotropic [10].

As for the heat conductivity test, all modified samples of the paint show better results than initial paint; the best result was shown by the sample 2 which comprises 1 mass. $\%$ of fullerene-containing soot. This means that the carbon particles included into charred layer increase its thermal stability; the mechanism of this effect is needed to be investigated.

The data presented by tables 3 and 4 shows the way of thermal decomposition of samples during TGA. Table 3 includes temperatures of main stages of composition's thermolysis; this data shows the extent of impact of different additives on the intumescent composition's thermolysis. The most significant changes are observed on the stages «synthesis of resin» and «condensation»; in samples 4 and 5 (containing microspheres) these stages shift to the area of higher temperatures. Also all additives shift the beginning of condensation to the area of lower temperatures. These effects may be explained by strengthening the carbon matrix of a charred layer by graphite-fullerene particles and infusible microspheres.

Table 4 shows the fact that all additives increase the heat endurance of an intumescent composition; this is proven by significant shifts of temperatures of start of sample's weight decrease and of full decay to the area of higher temperatures. The best results were shown by the sample 4 (containing glass microspheres).

\section{Conclusion}

Results of this research have shown that modification of intumescent paint by different additives is an effective way of improving their properties without the necessity of changing the fundamental composition of the paint. Additives described in the paper and suggested for using in intumescent technology are quite cheap and may be found exceedingly useful in fire protection of high-rise buildings.

The data provided by thermogravimetric analysis proves the stated facts and shows that modified intumescent paints are more reliable in case of fire.

The future line of this research is to describe in details the process of modification of intumescent compositions, the interaction between paint's components and additives. Also the firetests with real steel constructions have to be done.

\section{References}

1. L. Calabrese, F. Bozzoli, G. Bochicchio, B. Tessadri, S. Rainieri, G. Pagliarini, J. of Phys.: Conf. Ser., 547, 012005 (2014)

2. M. Gravit, V. Gumenyuk, O. Nedryshkin, Procedia Engineering 117, 114-118 (2015)

3. O. Zybina, M. Gravit, Y. Stein, IOP Conf. Ser.: Earth and Environmental Science, 90 (1), 012227

4. M. Gravit, V. Gumenyuk, M. Sychov, O. Nedryshkin, Procedia Engineering, 117, 119125 (2015)

5. R. B. R.S. Oliveira, A. L. Moreno Junior, L. C. M. Vieira, IBRACON Struct. and Mater. J., 10 (1), 220-243 (2017)

6. M. Gravit, S. Antonov, O. Nedryshkin, E. Nedviga, V. Pershakov, MATEC Web of Conf, 73, 04007 (2016)

7. M. Gravit, I. Dmitriev, A. Ishkov, IOP Conf. Ser.: Earth and Environmental Science, 90 (1), 012226, 2017 
8. V. Shilin, V. Sedov, Endohedral metallofullerenes of rare-earth elements. Part 1. The methods of their synthesis, PNPI, 38 p. (2012)

9. J. W. Robinson, E. M. Skelly Frame, G. M. Frame II, Undergraduate Instrumental Analysis, Sixth Edition, CRC Press, 1079 p. (2004)

10. O. Zybina Problemy tekhnologii koksoobrazuyushchikh ognezashchitnykh pokrytiy, CRNS, 51 p. (2010) 